\title{
BMJ Open Quality Reducing medical-surgical inpatient falls and injuries with videos, icons and alarms
}

\author{
Sasha J Cuttler, ${ }^{1,2}$ Jill Barr-Walker, ${ }^{3}$ Lauren Cuttler ${ }^{4}$
}

To cite: Cuttler SJ, BarrWalker J, Cuttler L. Reducing medical-surgical inpatient falls and injuries with videos, icons and alarms.BMJ Open Quality 2017;6:e00119. doi:10.1136/ bmjoq-2017-000119

Received 15 May 2017 Revised 30 September 2017 Accepted 3 October 2017

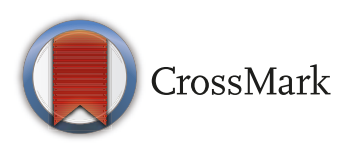

${ }^{1}$ Collaborative Alliance for Nursing Outcomes Coordinator, San Francisco General Hospital, San Francisco, California, USA ${ }^{2}$ Physiological Nursing, University of California San Francisco, San Francisco, California, USA

${ }^{3}$ ZSFG Library, University of California, San Francisco, California, USA

${ }^{4}$ Department of Nursing, City College of San Francisco, San Francisco, California, USA

Correspondence to Sasha J Cuttler, Collaborative Alliance for Nursing Outcomes Coordinator;

sasha.cuttler@sfdph.org

\section{ABSTRACT}

Background Inpatient falls and subsequent injuries are among the most common hospital-acquired conditions with few effective prevention methods.

Objective To evaluate the effectiveness of patient education videos and fall prevention visual signalling icons when added to bed exit alarms in improving acutely hospitalised medical-surgical inpatient fall and injury rates. Design Performance improvement study with historic control.

Setting Four medical-surgical units in one US public acute care hospital.

Study participants Adult medical-surgical inpatients units.

Interventions A 4 min video was shown to patients by trained volunteers. Icons of individual patient risk factors and interventions were placed at patients' bedsides. Beds with integrated three-mode sensitivity exit alarms were activated for confused patients at risk of falling.

Main outcome measures The main outcome measure is the incident rate per 1000 patient days (PDs) for patient falls, falls with any injury and falls with serious injury. The incident rate ratio (IRR) for each measure compared January 2009-September 2010 (baseline) with the followup period of January 2015-December 2015 (intervention). Results Falls decreased $20 \%$ from 4.78 to 3.80 per 1000 PDs (IRR $0.80,95 \% \mathrm{Cl} 0.66$ to 0.96 ); falls with any injury decreased $40 \%$ from 1.01 to 0.61 per 1000 PDs (IRR 0.60 , $95 \% \mathrm{Cl} 0.38$ to 0.94 ); and falls with serious injury $85 \%$ from 0.159 to 0.023 per 1000 PDs (IRR $0.15,95 \% \mathrm{Cl} 0.01$ to 0.85$)$. Icons were not fully implemented.

Conclusion The first known significant reduction of falls, falls with injury and falls with serious injury among medical-surgical inpatients was achieved. Patient education and continued use of bed exit alarms were associated with large decreases in injury. Icons require further testing. Multicentre randomised controlled trials are needed to confirm the effectiveness of icons and video interventions and exit alarms.

\section{INTRODUCTION}

Falling is a major public health problem with sequelae that range from minor bruises and abrasions to more serious consequences such as lacerations, fractures, head injuries and even death. ${ }^{1}$ Age-adjusted fall mortality rates have increased in recent years. ${ }^{1}$ Complications from falls while hospitalised are included on the Centers for Medicare and
Medicaid Services' list of non-reimbursable events. ${ }^{2}$ More than one million patients fall in US hospitals annually, accounting for $85 \%$ of all hospital-acquired conditions. ${ }^{3}$

Inpatient fall and injury incidence varies according to unit characteristics, ${ }^{4}$ with medical-surgical patients at higher risk than intensive care patients. Medical-surgical units in the USA report between 3.67 and 6.26 falls per 1000 patient days (PDs). ${ }^{4}$ Twenty per cent of medical-surgical unit falls result in some injury, while $2 \%$ result in serious injuries. ${ }^{4}$ The acute care patient may be at increased risk of falling due to newly altered mobility, medication side effects, history of previous falls, frequent toileting and altered mental status all in an unfamiliar environment.

As part of the 2010 US Patient Protection and Affordable Care Act, acute care hospitals were encouraged by the Partnership for Patients to test interventions to decrease patient falls and resultant injuries by $40 \% .^{5} \mathrm{By}$ the end of 2014, the Agency for Healthcare Research and Quality reported that hospital falls were essentially unchanged from 2010 levels. ${ }^{6}$ The lack of significant injury reduction despite years of effort and the finding that fall prevention efforts may not be cost-effective ${ }^{7}$ have contributed to frustration among researchers, healthcare workers and patients at risk. To improve patient and hospital staff satisfaction and prevent needless suffering, this study examines the efforts of one hospital's medical-surgical units to educate patients and staff via video, icons and alarms.

\section{BACKGROUND}

An urban public safety net hospital with a linguistically diverse patient population found that patient fall and injury rates were trending upwards. From 2009 through September 2010, fall prevention measures varied widely throughout the hospital. A 'falling star' magnet was placed on the door to the patient's room. This was meant to communicate to staff that the patient is at 
risk of falling. Unfortunately, staff found the star neither obvious nor indicative of particular interventions. ${ }^{8}$

Bed exit alarms could be ordered but this required extra steps. Failure of the patient to activate the call light was the most commonly cited explanation of the fall. Communication between nursing shifts and other units did not routinely include the patient's fall risk. Competing priorities for performance improvement such as physical restraint and pressure injury reduction were also being prioritised during this time.

In late 2010, VersaCare beds with built-in, three-sensitivity bed exit alarms were introduced. Staff were alerted when patients moved about in bed (most sensitive), are seated on the edge of bed (intermediate sensitivity) or are getting out of bed (least sensitive). This allowed nursing staff to come to the bedside before the patient had exited. The new beds also have a green indicator light that confirms that the bed is in its lowest position with the alarm set. Nurses were responsible for training their peers in the use of the new bed alarms; this training was anecdotally associated with a reduction in falls and injuries. The nurse managers reported that the early warning provided by the exit alarm allowed nurse assistants to be freed from close observation for only one patient at a time. Analysis of reported hospital falls by time of day found that injury was more frequent among the patients who fell during the night shift. Subsequent improvement work focused on encouraging nursing staff to consider using the exit alarm for confused patients at risk of falls, especially during the night.

In addition to continued use of the falling star and the three-mode bed exit alarm, in the time span of 2011 through 2014, the falls prevention team developed other interventions. Improvements included documentation and analysis of fall occurrences such as a 'post-fall huddle', collaboration with inpatient pharmacy to identify common medications that are risk factors for falls and development of a 10 min falls prevention video shown to all new clinical non-physician employees during orientation. It was also common for nursing staff to request a nurse assistant to perform close observation for individuals at risk of falls. However, the new measures fell short of expectations. Despite twice-daily screening of all medical-surgical inpatients with the Schmid screening tool, ${ }^{9}$ it was discovered that communication of falls risk among staff was inconsistent and patients were often unaware of their own risk. Yellow wrist bands indicating high fall risk were applied to patients in the emergency room but not used after admission to a medical-surgical unit as changes in patients' conditions would require placing and cutting off the wrist band frequently. Finally, in 2014, hospital staff decided to implement a patient safety education programme with volunteer-delivered multiple language videos and risk factor-specific fall icons.

The hospital also selected pressure ulcer injury prevention for team-based performance improvement during the same period. This provided an opportunity to retrospectively evaluate if there were any changes in the mobility of all medical-surgical patients. Physical restraints that prevent a patient from getting out of bed are also occasionally used on medical-surgical units. If falls were reduced by patients being confined to bed, then there could have been an increase in pressure ulcer injuries and/or the use of restraints.

\section{Primary aim}

Can medical-surgical inpatient falls and fall injuries be reduced by volunteer-administered video education and icons in addition to bed exit alarms?

\section{Literature review}

There are few published randomised controlled trials of fall prevention programmes in the acute care setting, and a recent meta-analysis of falls prevention found only a small reduction in falls. ${ }^{10}{ }^{11}$ Evidence of injury reduction is even more elusive, with few studies demonstrating significant improvement in fall injuries. ${ }^{12} 13$

Prevention programmes that have been widely implemented in acute care hospitals include screening patients with standardised risk assessments and addressing the risk with interventions including patient education, ${ }^{1014-17}$ falls risk warning signs (icons) ${ }^{14}$ and exit alarms ${ }^{18-21}$ that indicate when a patient is getting up without assistance.

A search was conducted in PubMed, Embase and the Cumulative Index to Nursing and Allied Health Literature using a variety of controlled vocabulary and keyword searches involving falls prevention, acute care and injuries. This comprehensive search revealed a gap: few studies of fall rates examined the effect of interventions on injury and injury severity. US hospitals appear to differ from other countries in standards for data collection and have different patient care environments (eg, open wards vs one or two patient beds per room), staffing characteristics, and much higher or lower baseline rates than Australia, ${ }^{22}$ the UK, ${ }^{23}{ }^{24}$ Ireland $^{25}$ and Singapore. ${ }^{26}$ Six US recent studies of falls injury prevention on acute inpatient medical-surgical units are summarised in table 1 .

Two studies used exit alarms, ${ }^{20} 21$ three included patient education ${ }^{1420} 27$ and two used icons or signs for visual signalling of fall risk. ${ }^{1420}$ Two studies reported a statistically significant decrease in falls, ${ }^{13} 14$ but only one reported a statistically significant decrease in falls with any injury. ${ }^{13}$ One of the few randomised controlled trials to demonstrate a statistically significant decrease in fall rates developed risk factor-specific icons that were printed automatically when the nurse performed the screening. ${ }^{14}$ The researchers designed icons based on each of the individual risk factors from the screening tool; these were tested in an iterative process. ${ }^{28}$ The object was to facilitate rapid identification of patients at risk and provide intuitively clear guidance on prospective interventions: for example, an icon showed a nurse assisting a patient to ambulate. In another study, volunteers in an Australian study provided companionship but not education and had no effect on fall rates. ${ }^{29}$ Patient education as a single 
Table 1 US medical-surgical fall and injury studies, 2009-2016

\begin{tabular}{|c|c|c|c|c|c|c|c|c|c|c|}
\hline \multirow{2}{*}{$\begin{array}{l}\text { Citation } \\
\text { Study type } \\
\text { Units (n) }\end{array}$} & \multirow[b]{2}{*}{ Interventions } & \multicolumn{3}{|c|}{$\begin{array}{l}\text { Falls } \\
1000 \text { patient days }\end{array}$} & \multicolumn{3}{|c|}{$\begin{array}{l}\text { Any injury } \\
1000 \text { patient days }\end{array}$} & \multicolumn{3}{|c|}{$\begin{array}{l}\text { Serious injury } \\
1000 \text { patient days }\end{array}$} \\
\hline & & Control & Intervention & p Value & Control & Intervention & p Value & Control & Intervention & p Value \\
\hline $\begin{array}{l}\text { DuPree et } a l^{21} \\
\text { Historic control } \\
14 \text { units }\end{array}$ & Exit alarms & 4.00 & 2.61 & * & 1.31 & 0.50 & * & * & * & * \\
\hline $\begin{array}{l}\text { Lohse et al }{ }^{13} \\
\text { Historic control } \\
1 \text { unit }\end{array}$ & $\begin{array}{l}\text { Timed } \\
\text { toileting }\end{array}$ & 4.24 & 2.53 & 0.02 & 1.17 & 0.41 & 0.04 & 0.000 & 0.160 & * \\
\hline $\begin{array}{l}\text { Titler et al }{ }^{40} \\
\text { Prospective } \\
\text { cohort } \\
13 \text { units }\end{array}$ & $\begin{array}{l}\text { Staff } \\
\text { education }\end{array}$ & 3.69 & 2.70 & 0.09 & 0.70 & 0.59 & 0.73 & * & * & * \\
\hline $\begin{array}{l}\text { Hardin et } a l^{20} \\
\text { RCT } \\
10 \text { units }\end{array}$ & $\begin{array}{l}\text { Icons } \\
\text { Patient } \\
\text { education } \\
\text { Exit alarm }\end{array}$ & 4.58 & 3.62 & 0.28 & * & * & * & 0.136 & 0.043 & 0.35 \\
\hline
\end{tabular}

Bold indicates statistically significant decrease in the intervention group. *Indicates insufficient data.

$\mathrm{RCT}$, randomised controlled trial.

intervention was found to be effective in reducing falls and injuries in an Australian randomised controlled trial, but this was in a rehabilitation setting with an average patient stay of $10-11$ days. ${ }^{30}$ DuPree $e t a l^{21}$ in their multicentre study reported a $62 \%$ decrease in injury, but no evidence is presented to suggest that the improvement was statistically significant, the criteria for unit selection are not included, and the follow-up period is not specified. Two recent randomised controlled trials of patient fall reduction programmes failed to demonstrate a reduction in injuries, ${ }^{143}$ and several quality improvement falls prevention studies fail to report injury rates ${ }^{1727}$ or demonstrate no change. ${ }^{2531}$ Weinberg et al ${ }^{12}$ reported a $64 \%$ decrease in serious injury falls over a 12-month period; however, injury outcome data were missing and the patient care units were heterogeneous. Quigley $e t a l^{27}$ reported a $55 \%$ reduction in serious falls but stated 'no significant trends in any direction', and a recent multicentre evaluation by the same author reported no changes in injuries. ${ }^{32}$ DuPree et al $\mathrm{s}^{21}$ multicentre study does not describe fall injury severity except to state 'there were no patient deaths as a result of a fall throughout the course of the project' (p100). Interventions in Lohse et $a l^{13}$ included assisted toileting and instructions to patients to remain in bed after surgery. Although they reported their study as the first to reduce acute inpatient falls and falls with injury, serious injuries do not appear to have decreased: there were no fractures or dislocations during the preintervention period and two such injuries postintervention.

\section{METHODS}

\section{Setting}

This performance improvement study was implemented in a US urban public safety net teaching hospital. Four medical-surgical units were selected. Two of the units had more surgical patients, and two others were designated acute care for elders units. Most of the patient rooms were shared by two patients; two of the units also had one room each with four patient beds to allow nursing staff to closely observe more vulnerable patients.

\section{Interventions}

Hospital staff were encouraged to submit images corresponding to each of the fall risk factors used to screen admitted patients every 12 hours. The images were evaluated by the falls task force and a patient advisor group. An illustrator developed icons to present to hospital staff, who agreed that the icons provided more information to the staff about individual patient risk than the falling star magnet. The icons were printed and mounted with a spiral binding to allow each to be flipped to the appropriate risk factor. They were mounted over the head of the bed, and staff were asked to adjust the icons to applicable risk status or to neutral position, based on screening results.

A 4 min video was produced with hospital staff and filmed in a patient room suggesting how a patient at risk of falls could mitigate their risk. Brochures were not used because of low literacy and numerous non-English languages spoken by the patients. The 4 min video 
featured hospital physicians, nurses, nurse assistants, pharmacists, social workers, and physical and occupational therapists, many of them bilingual. It was produced in English, Spanish, Tagalog and Cantonese versions. Nursing students and other community volunteers were trained to show the video on tablet devices to patients because there were no closed circuit televisions. Prospective volunteers were trained with the staff education video alongside new clinical staff. After completing an online volunteer training, the volunteers were trained on the unit one-on-one by study author or research assistant. The training included how to activate the call lights if patients were getting out of bed. The tablet device was placed in a disposable transparent sleeve and sanitised between patients. Patients who screened as at risk of falling (using the Schmid ${ }^{9}$ screening tool) were identified on a computer-generated list and the volunteers were encouraged to ask nursing staff for individual patients to educate (eg, present on the unit and awake) or avoid (eg, on isolation or a history of violence). Bilingual volunteers would often select patients whose language they spoke. The video described some of the risk factors, such as an unfamiliar environment especially at night, new medications, and temporary weakness and dizziness. The video demonstrated a patient and nurse placing belongings in reach, using the call light and waiting, letting the nurse know when visitors leave, requesting a bedside commode, and accepting staff presence while toileting. The volunteers did not provide hands-on assistance or perform assessments. Although there was no formal knowledge assessment, volunteers were encouraged to ask patients to identify falls prevention measures that applied to them. The video was offered to patients and their families at any point during their hospitalisation. Volunteers were encouraged to offer multiple viewings and to enlist visitors' support and were instructed to share their observations with the nursing staff assigned to the patient's care. Because confusion is one of the risk factors for falling, the video was also shown to patients with cognitive impairment. Volunteers were instructed to reinforce the information as simply as possible, particularly for confused patients. Seventeen patient teaching points are demonstrated in the video.

From late 2010 through 2015, nurses were encouraged to continue to use the integrated three-mode bed exit alarms, especially at night-time and for confused fall risk patients who could not reliably use the call light.

Both the icons and the videos were developed and piloted on the acute care for elders unit with behavioural patients because this unit had the most patients at risk of falls and injury as well as the most frequent falls. Piloting began during the last quarter of 2014 and spread to all medical-surgical units in January 2015. Figure 1 depicts the icons used in this study, along with nursing interventions and video teaching points associated with each.

\section{Data collection}

Patient falls were defined as an unintentional descent to a lower elevation with or without a hospital staff observing or physically assisting the patient down. When a patient fell, hospital staff provided assistance or first aid and notified the physician. Clinical follow-up was variable and depending on the circumstances of the fall, such as apparent injury, height of fall, whether there was loss of consciousness or if the patient's head struck the floor. A narrative description of the fall incident was reported electronically to the hospital's unusual occurrence database. The unit's clinical nurse specialist or nurse manager investigated the fall by speaking to witnesses and consulting the medical record. The investigator determined if the fall was observed or assisted by hospital staff, if the patient was restrained at the time of the fall and the severity of injury if any. Injuries were defined as either minor (bruise, abrasion or pain 24 hours after the event), moderate (laceration that required skin glue, Steri-Strips or suturing) or major (fracture, subdural haematoma, blood products required or death). Data were not collected regarding any increased length of stay or transfer to a higher level of care. The patient's age and gender were also collected and the de-identified data were submitted quarterly to the Collaborative Alliance for Nursing Outcomes (CALNOC), a voluntary nursing measures unit-based data repository. ${ }^{36}$ The number of patient bed days per month was also reported to CALNOC. To protect patient privacy, falls were counted rather than individual fallers as is standard in US unit-based databases. All measures were in alignment with the CALNOC codebook. There were no significant changes in data definitions, collection or methods over the course of the study. The period January 2009-September 2010 (seven quarters) was selected as the baseline because this preceded the introduction of VersaCare hospital beds with integrated three-mode bed exit alarms. The follow-up period of January-December 2015 (four quarters) was selected because the video and icons were in use in all of the medical-surgical units. Frequencies of viewings of the video and comments were maintained on the tablet devices.

To evaluate if there was a change in medical-surgical patient mobility or morbidity, the point prevalence was calculated for pressure injuries, ${ }^{33}$ physical restraint ${ }^{34}$ and the use of close observation by nurse assistants. ${ }^{35}$ Data on each of these indicators were collected quarterly by the hospital staff. The denominator for the quarterly survey is the number of patients on each medical-surgical unit. As a marker of patient morbidity, the quarterly percentage of medical-surgical patients at risk of pressure ulcers (Braden score 18 and under) was also calculated. The quarterly survey data were also collected and reported using CALNOC standardised methodology. ${ }^{36}$

\section{Data analysis}

The rate for all falls (with or without injury), falls with any injury (minor, moderate or major) and falls with serious injury (moderate and major injury only) were all 

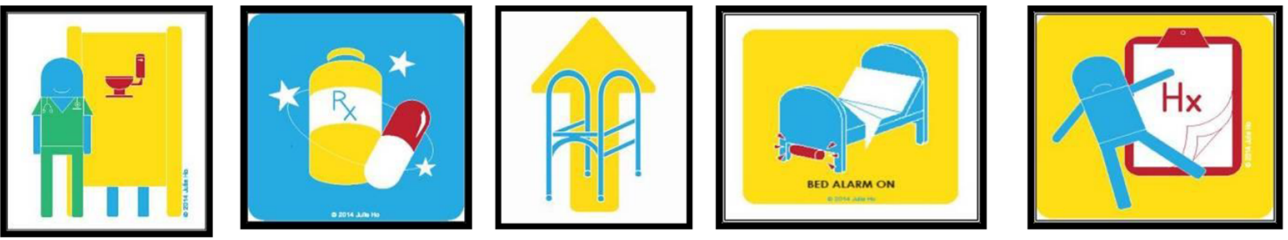

\begin{tabular}{|c|c|c|c|c|c|}
\hline Schmid $^{18}$ & Elimination & Medication & Mobility & Mentation & Fall History \\
\hline $\begin{array}{l}\text { Risk } \\
\text { factor }\end{array}$ & $\begin{array}{l}\text { Frequency } \\
\text { Incontinence } \\
\text { Diarrhea }\end{array}$ & $\begin{array}{l}\text { Anti-convulsant } \\
\text { Sedative }\end{array}$ & $\begin{array}{l}\text { Unsteady gait } \\
\text { Needs assist } \\
\text { by nurse or } \\
\text { device }\end{array}$ & $\begin{array}{l}\text { Periodic or constant } \\
\text { confusion }\end{array}$ & $\begin{array}{l}\text { Unknown or before } \\
\text { admission } \\
\text { Fall during current } \\
\text { admission }\end{array}$ \\
\hline $\begin{array}{l}\text { Staff } \\
\text { response }\end{array}$ & $\begin{array}{l}\text { Preventive } \\
\text { toileting } \\
\text { Supervised } \\
\text { toileting } \\
\text { Obtain } \\
\text { commode }\end{array}$ & $\begin{array}{l}\text { Consider change } \\
\text { in regimen } \\
\text { Instruct patient } \\
\text { in side effects }\end{array}$ & $\begin{array}{l}\text { Keep device in } \\
\text { reach }\end{array}$ & $\begin{array}{l}\text { Consider bed alarm } \\
\text { especially at night } \\
\text { Assess and report } \\
\text { changes } \\
\text { Frequent reminders } \\
\text { to call }\end{array}$ & $\begin{array}{l}\text { Prioritize for } \\
\text { education and } \\
\text { enhanced } \\
\text { interventions } \\
\text { Report fall history } \\
\text { between shifts and at } \\
\text { transfer }\end{array}$ \\
\hline $\begin{array}{l}\text { Patient } \\
\text { video }\end{array}$ & $\begin{array}{l}\text { Staff may } \\
\text { supervise } \\
\text { Commode may } \\
\text { be safer } \\
\text { Most common } \\
\text { activity while } \\
\text { falling }\end{array}$ & $\begin{array}{l}\text { New regimen } \\
\text { may have side } \\
\text { effects } \\
\text { Dizziness }\end{array}$ & $\begin{array}{l}\text { Staff assist } \\
\text { Device } \\
\text { Keep items in } \\
\text { reach } \\
\text { Change } \\
\text { position slowly } \\
\text { Non-skid socks }\end{array}$ & $\begin{array}{l}\text { Unfamiliar } \\
\text { environment } \\
\text { Night risk-sleep } \\
\text { inertia } \\
\text { Dizziness should be } \\
\text { reported } \\
\text { Call and wait } \\
\text { Use sensory aids }\end{array}$ & $\begin{array}{l}\text { Not addressed in } \\
\text { video }\end{array}$ \\
\hline
\end{tabular}

Figure 1 Falls prevention icons with staff interventions and patient video teaching points.

calculated as $1000 \times$ the number of events divided by the number of PDs. The proportion of falls resulting in injury was calculated by dividing the number of falls with any injury by all the falls. Descriptive statistics of frequency, mean and SD were calculated. Bivariate statistics were calculated by Student's t-test for continuous measures and $\chi^{2}$ for categorical measures. The incident rate ratio (IRR) compared the intervention period rates with the baseline period. The $95 \%$ two-sided CI was calculated and statistical significance was established as $p<0.05$. Statistics were calculated using the OpenEpi software. ${ }^{37}$

\section{RESULTS}

During the 7-year period of January 2009 through December 2015, 1215 patient falls were recorded on medical-surgical units. Of the 1215 patient falls, 239 $(20 \%)$ resulted in any injury. All three outcome measures declined after the baseline period during the last quarter of 2010 after the introduction of the new hospital beds with three-mode bed exit alarms (figure 2). The average age of fallers was 56 years old, $21 \%$ were 65 and older, and $32 \%$ were women. The baseline period from January 2009 through September 2010 included 75293 PDs or about 10756 days per quarter. The intervention period of January 2015 through December 2015 included
42580 PDs or about 10645 days per quarter. The mean difference in days per quarter was not statistically significant. The average daily census of 30 patients on each unit was also stable.

Patients and family members were approached approximately 1200 times by trained volunteer educators who showed the video and informally discussed risk reduction. Patients and family members most frequently cited the importance of using the call light. The icons were posted over 10 beds, but were infrequently adjusted and therefore not spread to all beds.

Table 2 presents the fall and injury rates at baseline and during the intervention.

The falls rate during 2015 showed a statistically significant decrease from baseline. The IRR of 0.80 ( $\mathrm{p}=0.01$, $95 \%$ CI 0.66 to 0.96 ) represents a $20 \%$ reduction in all falls during the intervention period. The percentage of falls with injury decreased from $21 \%$ during the baseline period to $16 \%$ in 2015 . For falls resulting in injury, the IRR of $0.60(\mathrm{p}=0.02,95 \%$ CI 0.38 to 0.94$)$ represents a $40 \%$ reduction during the intervention period.

Serious injuries (moderate or major) remained infrequent after the baseline period. During the baseline period there were 12 falls that resulted in lacerations, fractures, dislocations or subdural haematoma. During the 

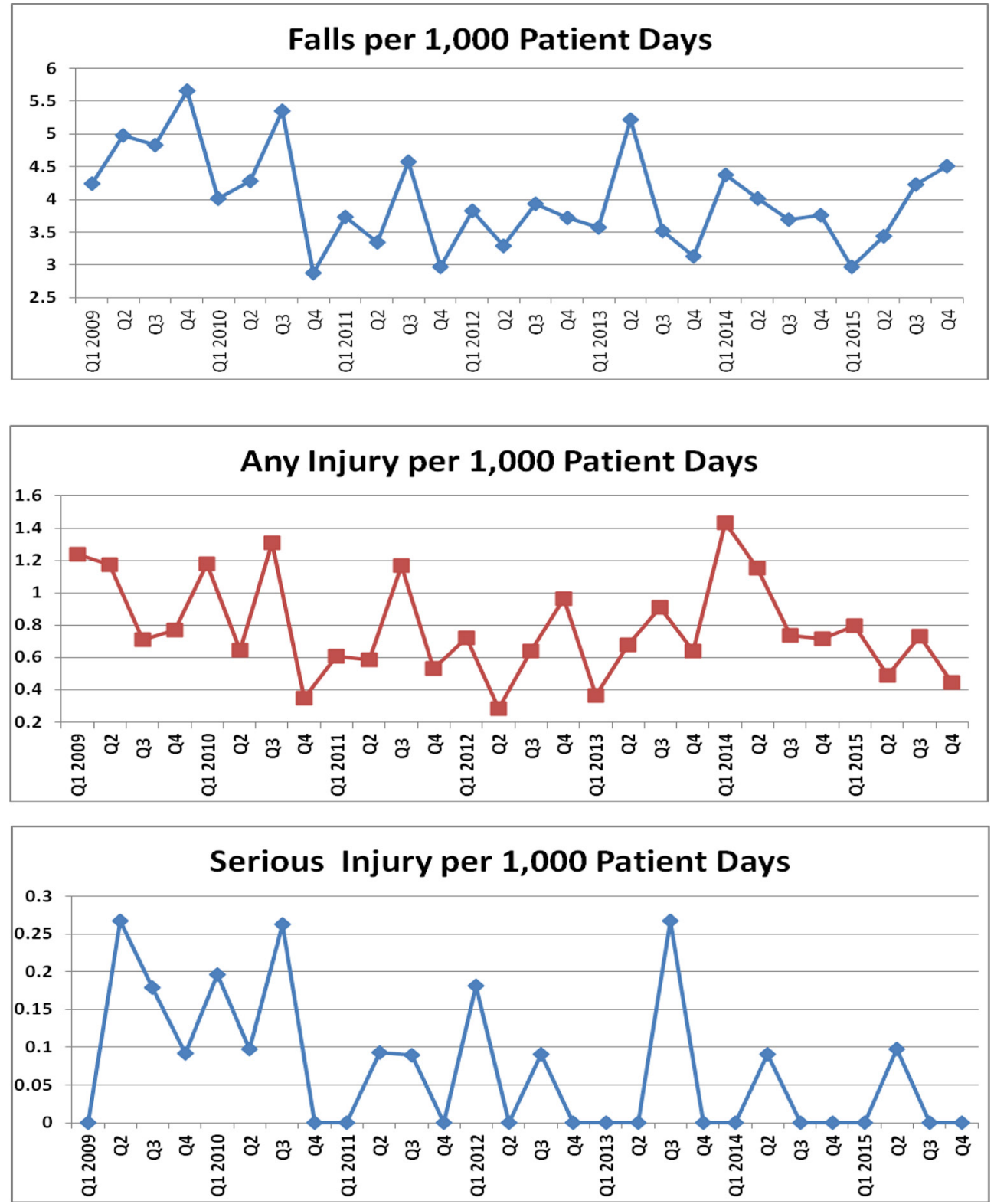

Figure 2 Medical-surgical unit patient falls, falls with any injury and falls with serious injury per 1000 patients days, January 2009-December 2015.

\begin{tabular}{|c|c|c|c|}
\hline & $\begin{array}{l}\text { January 2009- } \\
\text { September 2010 }\end{array}$ & $\begin{array}{l}\text { January 2015- } \\
\text { December } 2015\end{array}$ & $\begin{array}{l}\text { Incident rate ratio } \\
(95 \% \mathrm{Cl})\end{array}$ \\
\hline Total number of patient days (PDs) & 75293 & 42580 & \\
\hline Total number of falls & 360 & 162 & \\
\hline Falls per $1000 \mathrm{PD} \pm \mathrm{SD}$ & $4.78 \pm 0.57$ & $3.80 \pm 0.61$ & 0.80 (0.66 to 0.96$)$ \\
\hline Total injured, $\mathrm{n}(\%)$ & $76(21 \%)$ & $26(16 \%)$ & \\
\hline Any injury per $1000 \mathrm{PD} \pm \mathrm{SD}$ & $1.01 \pm 0.26$ & $0.61 \pm 0.15$ & 0.60 (0.38 to 0.94$)$ \\
\hline No injury, n (\%) & $284(79 \%)$ & $136(84 \%)$ & \\
\hline Minor injury, $\mathrm{n}(\%)$ & $64(18 \%)$ & $25(15 \%)$ & \\
\hline Moderate injury, $\mathrm{n}(\%)$ & $5(1 \%)$ & $1(1 \%)$ & \\
\hline Major injury, n (\%) & $7(2 \%)$ & 0 & \\
\hline Serious injury per $1000 \mathrm{PD} \pm \mathrm{SD}$ & $0.159 \pm 0.091$ & $0.023 \pm 0.042$ & $0.15(0.01$ to 0.85$)$ \\
\hline
\end{tabular}


four quarters of 2015 , there was only one moderate injury fall, which resulted in a laceration requiring suturing. For falls resulting in serious injury, the IRR of $0.15(\mathrm{p}=0.03$, $95 \%$ CI 0.01 to 0.85 ) indicates an $85 \%$ reduction during the intervention period. There were no deaths as a result of a patient fall from 2009 through 2015.

The proportion of falls that were observed by a staff member more than doubled from $13.27 \%$ (SD 8.32) during the baseline period to $28.03 \%$ (SD 4.94) in 2015, and this was statistically significant $(\mathrm{p}=0.01,95 \%$ CI 4.31 to 25.21). Falls that were physically assisted by staff as the patient fell increased from 2.78\% (SD 2.10) to $15.09 \%$ (SD 8.54), but this was not statistically significant ( $\mathrm{p}=0.07,95 \%$ CI -1.51 to 26.13$)$.

Hospital-acquired pressure ulcer injuries (all categories) decreased during the same period from $3.24 \%$ (SD 1.23 ) in 2009-Q3 2010 to $0.21 \%$ (SD 0.42) in 2015, and this was statistically significant $(\mathrm{p}<0.00,95 \%$ CI 1.56 to $4.50)$. The percentage of patients at risk of skin injury (Braden 18 and lower) at admission to the hospital was unchanged from 48.87\% (SD 7.95) in 2009-Q3 2010 to $50.81 \%$ (SD 3.83) ( $\mathrm{p}=0.66)$. Restraint prevalence was also stable with the apparent decrease from $2.14 \%$ (SD 1.79) in the baseline period to $0.88 \%$ (SD 0.77 ), not statistically significant $(\mathrm{p}=0.22)$. The proportion of patients under close observation by a nurse assistant decreased significantly from the baseline $17.87 \%$ (SD 1.88) to $11.83 \%$ (SD 2.84) $(\mathrm{p}<0.00,95 \%$ CI 2.86 to 9.22$)$.

\section{DISCUSSION}

In 2015, all three falls outcome measures were significantly reduced for the first time in 6 years. When volunteer-delivered education videos and three-mode bed exit alarms were used, a significant decrease was observed in patient falls $(20 \%)$, falls with any injury $(40 \%)$ and falls with serious injury $(85 \%)$. Injury reduction met and serious injury reduction exceeded the Partnership for Patients goal of a $40 \%$ reduction.

In contrast to previous studies, this study found positive results from the use of bed exit alarms. This is the first known study to examine the effects of an exit alarm that is integrated into the bed. The improvement sustained in the current study may be attributable to targeting patients who stood to benefit: nursing staff were instructed to select patients who were both at risk of falls and subsequent injury and unable or unwilling to reliably use the call bell. Such risk stratification may help avoid alarm fatigue. Nursing staff believed that use of the exit alarm helps by freeing up staff from continuous observation because it functions as an extra 'call light'. Quarterly survey data on medical-surgical units showed a modest decrease in the percentage of patients with close observation by nurse assistants from $18 \%$ during the baseline period to $12 \%$ in 2015 . Nonetheless, staff were twice as likely to witness a patient fall in 2015 as they were during the baseline period. Although the increase in falls physically assisted by a staff number was not statistically significant, the opportunity to reach the patient just before falling appears to have increased in the follow-up period. It is also possible that the sound stimulus delays or stops the patient's bed exit. The finding that injuries and especially serious injuries were reduced supports the theory that the three-mode bed exit alarm alerts staff before the patient is fully standing and ambulating and at risk of striking the floor at a higher velocity.

The falls icons were never fully implemented because adherence was challenging. Unlike the Dykes $e t a l^{14}$ study, the icons were not printed automatically when the nurse screened the patient. When icons were placed above the head of the patient's bed, it was physically difficult to adjust them. Because falls screening is done every 12-hour shift by the registered nurse, it was necessary to adjust the icons twice a day per patient. Training was inadequate and there was concern about excessive visual signalling as the icons were added to the falling star magnet on the patient's room doorway. Future work being considered includes placement of falls prevention icons on erasable board (white board) visible to all who enter the room, as well as the patients and their family. In order to decrease the number of icons, it may be useful to focus on a single visual reminder to mobilise with assistance. Any changes and tests of icons should include front-line staff as well as patients.

The falls prevention video was more widely accepted by patients, their family and hospital staff. The volunteers reported that patients were engaged and often surprised to learn that they had been screened as at risk of falling. The medical-surgical patients in the current study had a shorter length of stay, which may decrease the amount of time at risk of falling but also reduces the amount of time available for patient education. The video available in four languages and the bilingual patient education volunteers may have been more helpful than a brochure in a low literacy environment and may have improved communication between patients and their caregivers. ${ }^{38}$ The novelty of receiving a visit from a volunteer with a video on a tablet device may have increased the retention of information by the patients. Anecdotally, patients were more engaged by the videos because they featured hospital staff addressing the patients in their environment.

It was gratifying to note that falls and injury reduction was not achieved at the cost of patient autonomy (restraint prevalence unchanged) or mobility (hospital-acquired pressure ulcer injury prevalence decreased from $3 \%$ to less than $1 \%$ ). There was no change noted in patient vulnerability, with approximately half of all medical-surgical patients at risk of injury throughout both the baseline and follow-up periods.

Falls and injury prevention programmes are challenging to evaluate for cost-effectiveness. ${ }^{7}$ In the current study, the three-mode bed exit alarm was already integrated into the bed for each inpatient, so it was not possible to evaluate this cost. Additional costs were incurred for tablet devices to show video to patients and for printing icons. 
This performance improvement study has several limitations. The lack of randomisation or contemporaneous comparison group inherent to the study design makes it difficult to infer that the interventions were associated with the improvement observed. The principal investigator and hospital staff were not blinded to the interventions. Multiple interventions for patient safety were implemented during this time, all of which may have contributed to fewer falls and injuries. The lack of an attention control means that specific elements of the icons and patient video may have been less important than the novelty of each method and/or the presence of a friendly volunteer. The nursing unit level of data measurement prevents evaluation of the effect on individual patients. Measuring falls rather than unique fallers makes it difficult to evaluate the effectiveness of interventions to prevent multiple falls by individual patients. If risk factors for falling more than once can be identified, then educational interventions could be targeted appropriately. To protect individual patient privacy, it is unknown which of the fallers received the video education or had the icons posted over the head of their beds. There may have been changes in potential effect modifiers such as patient morbidity or length of hospitalisation. Characteristics of the patient room such as proximity to the nursing station and the presence or absence of roommates were not collected. Roommates may also benefit from the proximity of staff attending to patients. The environment of care should be considered as there is some evidence that isolating patients in private rooms may lead to increased risk because staff cannot visualise more than one patient at a time. ${ }^{39}$

\section{CONCLUSION}

Brief video education of medical-surgical inpatients on fall risk in conjunction with the use of three-mode bed exit alarms was shown to be both feasible and effective The use of standardised reporting methods increases confidence that the observed improvement was due to the interventions. That there was no significant change in the age, gender and morbidity of the fallers suggests that the results were not affected by those known confounders. The efforts to risk-stratify with the use of the existing screening tool and the availability of an electronically generated list of patients at risk may have helped to identify prospective interventions for individual patient risk factors. It is unknown if there is an ideal time to provide the education to patients during their stay in hospital. Patients are more likely to be mobile by the end of their hospitalisation than when they arrive. Although they are less debilitated, there are more opportunities for an ambulatory patient to fall.

Future prospective trials should evaluate the effectiveness of fall and injury prevention programmes that control for known risk modifiers such as patient age, gender, length of stay and admitting diagnosis, as well as nurse staffing. Fall prevention trials should report on injuries as well as fall rates. The reduction of patient injury should be the primary goal of a fall prevention programme. As stated by the acute care for elders clinical nurse specialist at the end of the patient education video: "We don't want anyone to get hurt while they are in the hospital."

Acknowledgements In addition to thanking the volunteers and the medicalsurgical bed-side nurses and certified nurse assistants and each of the hospital staff who appear in the video who implement safety measures continuously and tirelessly , the authors wish to acknowledge the work of interdisciplinary falls prevention team members: Dana Freiser RN BSN, Annelie C. Nilsson RN MSN CNS, Janet Kosewic RN MSN CNL, Purificacion Quevedo-Maghinang RN MA, Thomas Holton RN MS CPPS, Amy Murphy RN CNL, Chad Belicena RN MSN, Bonnie Seaman PT, Margarita Sotelo MD, Linda Lee RN BSN, Kathy Ballou RN MSN, David Rubin RN, Jeanette Cavano PharmD, Irina Gruzman RN, Patrick Nagle RN BSN, Michelle Reyes PT DPT, and Rachel Limon Perry RN MS CNS; Clinical Nurse Educators: Monique DeRouen Lowerre RN BSN, Elizabeth Adviento RN BSN, Jennifer Berke RN MSN MPA, and Anita Roberts RN MSN; Community advisor coordinators: Rachael Kagan and Arla Escontrias; Video production: Ben Briones MS, Video translators: Mari Mo and Liliana Diaz MSW; Icon design: Ferdinand Mabaet RN andJulie Ho BFA ; Improvement coaching: America's Essential Hospitals Hospital Engagement Network; CALNOC and Evidence-Based Practice Fellowship Program: Mary Foley RN PhD; Research assistants: Sarah Lougher Bertero RN BSN PHN, Monica Jensen Certified Nursing Assistant, and Emerson Sosa BS; Literature Review:Librarians Stephen Kiyoi MLIS, and Charlotte Kuo RN NP; Joanna Briggs Institute UCSF Centre: Michelle Lieggi MLS AHIP and Daphne Stannard RN PhD; Nursing administration: Leslie Holpit RN MSN; Education and Volunteer Coordination: Kala Garner MA , Akilah Cadet MPH DHSc , Joseph Griffin MPH, and Harold Santos BS; Data consultants and editorial services: Nancy Gordon MS and Alice Webber PhD; Critical review: Liz Charalambous RN BSc (hons) MSc, Sarah Goldberg RN PhD, Joanne Cooper RN PhD, and Judy Kleppel MD MPH Encouragement to publish: Joseph Clement RN MN CCNS, Cynthia Johnson RN NP, Cheryl Kalson MHA, Jessica Morton MA and Suk Chung RN NP; Professional Organization: Service Employees International Union Nurse Alliance.

Contributors SJC was the principal investigator who initiated and designed the study, coordinated the implementation and analysed the data. JBW assisted with the literature review. LC cowrote and directed the patient education video.

Funding Hill-Rom Inc. supported the study to fund the production of the patient education video, loan of the tablet devices, preparation and mounting of the icons, stipend for research assistants, statistics consultant, open access fee and editing of manuscript. Hill Rom Inc. had no role in the design and conduct ofthe study; collection, analysis, or interpretation of the data; or preparationor approval of the manuscript

Competing interests None declared.

Ethics approval According to the policy regarding activities that constitute research at the hospital, this study met the criteria for operational improvement activities exempt from human subjects institutional review board review. Volunteers and staff were instructed to protect patient confidentiality and data were de-identified before submission for data analysis.

Provenance and peer review Not commissioned; externally peer reviewed.

Data sharing statement The complete set of icons is available upon email request from the corresponding author (SJC).

Open Access This is an Open Access article distributed in accordance with the Creative Commons Attribution Non Commercial (CC BY-NC 4.0) license, which permits others to distribute, remix, adapt, build upon this work non-commercially, and license their derivative works on different terms, provided the original work is properly cited and the use is non-commercial. See: http://creativecommons.org/ licenses/by-nc/4.0/

(C) Published by the BMJ Publishing Group Limited. For permission to use (where not already granted under a licence) please go to http://www.bmj.com/company/ products-services/rights-and-licensing/

\section{REFERENCES}

1. Rockett IR, Regier MD, Kapusta ND, et al. Leading causes of unintentional and intentional injury mortality: United States, 20002009. Am J Public Health 2012;102:e84-e92. 
2. Waters TM, Daniels MJ, Bazzoli GJ, et al. Effect of Medicare's nonpayment for Hospital-Acquired Conditions: lessons for future policy. JAMA Intern Med 2015;175:347-54.

3. Attenello FJ, Wen T, Cen SY, et al. Incidence of "never events" among weekend admissions versus weekday admissions to US hospitals: national analysis. BMJ 2015;350:h1460.

4. Williams T, Szekendi M, Thomas S. An analysis of patient falls and fall prevention programs across academic medical centers. J Nurs Care Qual 2014;29:19-29.

5. Welcome to the Partnership for Patients Baltimore. Centers for medicare and medicaid services. Maryland, US: Welcome to the Partnership for Patients Baltimore. https://partnershipforpatients.cms gov/ (accessed Aug 16 2016)

6. Saving lives and saving money: hospital-acquired conditions updateinterim data from national efforts to make care safer, 20102014. Rockville MD: Agency for Healthcare Research and Quality, 2015. http://www.ahrq.gov/professionals/quality-patient-safety/pfp/ interimhacrate2014.html. (accessed 24 Aug 2016).

7. Spetz J, Brown DS, Aydin C. The economics of preventing hospital falls: demonstrating ROI through a simple model. J Nurs Adm 2015:45:50-7.

8. Dykes PC, Carroll DL, Hurley AC, et al. Why do patients in acute care hospitals fall? Can falls be prevented? J Nurs Adm 2009;39:299-304.

9. Schmid NA. 1989 Federal Nursing Service Award Winner. Reducing patient falls: a research-based comprehensive fall prevention program. Mil Med 1990;155:202-7.

10. DiBardino D, Cohen ER, Didwania A. Meta-analysis: multidisciplinary fall prevention strategies in the acute care inpatient population. $J$ Hosp Med 2012;7:497-503.

11. Miake-Lye IM, Hempel S, Ganz DA, et al. Inpatient fall prevention programs as a patient safety strategy: a systematic review. Ann Intern Med 2013;158:390-6.

12. Weinberg J, Proske D, Szerszen A, et al. An inpatient fall prevention initiative in a tertiary care hospital. Jt Comm J Qual Patient Saf 2011;37:317-AP2.

13. Lohse GR, Leopold SS, Theiler S, et al. Systems-based safety intervention: reducing falls with injury and total falls on an orthopaedic ward. J Bone Joint Surg Am 2012;94:1217-22.

14. Dykes PC, Carroll DL, Hurley A, et al. Fall prevention in acute care hospitals: a randomized trial. JAMA 2010;304:1912-8.

15. Krauss MJ, Tutlam N, Costantinou E, et al. Intervention to prevent falls on the medical service in a teaching hospital. Infect Control Hosp Epidemiol 2008;29:539-45.

16 Haines TP, Hill AM, Hill KD, et al. Patient education to prevent falls among older hospital inpatients: a randomized controlled trial. Arch Intern Med 2011;171:516-24.

17. Lancaster $A D$, Ayers $A$, Belbot $B$, et al. Preventing falls and eliminating injury at Ascension Health. Jt Comm J Qual Patient Saf 2007:33:367-75.

18. Hoke LM, Guarracino D. Beyond socks, signs, and alarms: a reflective accountability model for fall prevention. Am J Nurs 2016;116:42-7.

19. Shorr RI, Chandler AM, Mion LC, et al. Effects of an intervention to increase bed alarm use to prevent falls in hospitalized patients: a cluster randomized trial. Ann Intern Med 2012;157:692-9.

20. Hardin SR, Dienemann J, Rudisill $P$, et al. Inpatient fall prevention: use of in-room Webcams. J Patient Saf 2013:9:29-35.
21. DuPree E, Fritz-Campiz A, Musheno D. A new approach to preventing falls with injuries. J Nurs Care Qual 2014;29:99-102.

22. Barker AL, Morello RT, Wolfe R, et al. 6-PACK programme to decrease fall injuries in acute hospitals: cluster randomised controlled trial. BMJ 2016;352:h6781.

23. Sahota O, Drummond A, Kendrick D, et al. REFINE (REducing Falls in In-patieNt Elderly) using bed and bedside chair pressure sensors linked to radio-pagers in acute hospital care: a randomised controlled trial. Age Ageing 2014;43:247-53.

24. Drahota AK, Ward D, Udell JE, et al. Pilot cluster randomised controlled trial of flooring to reduce injuries from falls in wards for older people. Age Ageing 2013;42:633-40.

25. Galbraith JG, Butler JS, Memon AR, et al. Cost Analysis of a Fallsprevention Program in an Orthopaedic Setting. Clinical Orthopaedics and Related Research $₫ 2011 ; 469: 3462-8$.

26. Mordiffi SZ, Ng SC, Ang NKE, et al. A 10-year journey in sustaining fall reduction in an academic medical center in Singapore. Int J Evid Based Healthc 2016;14:24-33.

27. Quigley PA, Hahm B, Collazo S, et al. Reducing serious injury from falls in two veterans' hospital medical-surgical units. J Nurs Care Qual 2009;24:33-41.

28. Dykes PC, Carroll D, McColgan K, et al. Scales for assessing selfefficacy of nurses and assistants for preventing falls. J Adv Nurs 2011;67:438-49.

29. Giles LC, Bolch D, Rouvray R, et al. Can volunteer companions prevent falls among inpatients? A feasibility study using a pre-post comparative design. BMC Geriatr 2006;6:11.

30. Hill AM, McPhail SM, Waldron N, et al. Fall rates in hospital rehabilitation units after individualised patient and staff education programmes: a pragmatic, stepped-wedge, cluster-randomised controlled trial. Lancet 2015;385:2592-9.

31. Williams TA, King G, Hill A-M, et al. Evaluation of a falls prevention programme in an acute tertiary care hospital. $J$ Clin Nurs 2007:16:316-24.

32. Quigley PA, Barnett SD, Bulat T, et al. Reducing falls and fallrelated injuries in medical-surgical units: one-year multihospital falls collaborative. J Nurs Care Qual 2016;31:139-45.

33 Aydin C, Donaldson N, Aronow HU, et al. Improving hospital patient falls: leveraging staffing characteristics and processes of care. J Nurs Adm 2015;45:254-62.

34. Tan KM, Austin B, Shaughnassy M, et al. Falls in an acute hospital and their relationship to restraint use. Ir J Med Sci 2005;174:28-31.

35. Lang CE. Do sitters prevent falls? A review of the literature. $J$ Gerontol Nurs 2014;40:24-33.

36. Brown DS, Donaldson N, Burnes Bolton L, et al. Nursing-sensitive benchmarks for hospitals to gauge high-reliability performance. $J$ Healthc Qual 2010;32:9-17.

37. OpenEpi: Open source epidemiologic statistics for public health [program]. 3.01 version.

38. Schillinger D, Bindman A, Wang F, et al. Functional health literacy and the quality of physician-patient communication among diabetes patients. Patient Educ Couns 2004;52:315-23.

39. Singh I, Okeke J. Risk of inpatient falls is increased with single rooms. BMJ 2013;347:f6344.

40. Titler MG, Conlon P, Reynolds MA, et al. The effect of a translating research into practice intervention to promote use of evidence-based fall prevention interventions in hospitalized adults: A prospective prepost implementation study in the U.S. Appl Nurs Res 2016;31:52-9. 